\title{
Autonomic Dysreflexia Causes Chronic Immune Suppression after Spinal Cord Injury
}

\author{
Yi Zhang, ${ }^{1,2}$ Zhen Guan, ${ }^{1,2}$ Brenda Reader, ${ }^{3,7}$ Todd Shawler, ${ }^{4}$ Shweta Mandrekar-Colucci, ${ }^{1,2}$ Kun Huang, ${ }^{5}$ Zachary Weil, ${ }^{2}$ \\ Anna Bratasz, ${ }^{6}$ Jonathan Wells, ${ }^{3,7}$ Nicole D. Powell, ${ }^{3,7}$ John F. Sheridan, ${ }^{3,7}$ Caroline C. Whitacre, ${ }^{4,7}$ \\ Alexander G. Rabchevsky, ${ }^{8}$ Mark S. Nash,,${ }^{9,10}$ and Phillip G. Popovich ${ }^{1,2,7}$ \\ ${ }^{1}$ Center for Brain and Spinal Cord Repair, ${ }^{2}$ Department of Neuroscience, ${ }^{3}$ Division of Oral Biology, College of Dentistry, ${ }^{4}$ Department of Microbial Infection \\ and Immunity, and ${ }^{5}$ Department of Biomedical Informatics, Wexner Medical Center, ${ }^{6}$ Small Animal Imaging Shared Resources, and ${ }^{7}$ Institute for \\ Behavioral Medicine Research, The Ohio State University, Columbus, Ohio 43210, ${ }^{8}$ Department of Physiology, Spinal Cord and Brain Injury Research \\ Center, University of Kentucky, Lexington, Kentucky 40536, ${ }^{9}$ Department of Neurological Surgery and Rehabilitation Medicine and ${ }^{10} \mathrm{The}$ Miami Project to \\ Cure Paralysis, University of Miami Miller School of Medicine, Miami, Florida 33136
}

Autonomic dysreflexia (AD), a potentially dangerous complication of high-level spinal cord injury (SCI) characterized by exaggerated activation of spinal autonomic (sympathetic) reflexes, can cause pulmonary embolism, stroke, and, in severe cases, death. People with high-level SCI also are immune compromised, rendering them more susceptible to infectious morbidity and mortality. The mechanisms underlying postinjury immune suppression are not known. Data presented herein indicate that AD causes immune suppression. Using in vivo telemetry, we show that $\mathrm{AD}$ develops spontaneously in SCI mice with the frequency of dysreflexic episodes increasing as a function of time postinjury. As the frequency of $\mathrm{AD}$ increases, there is a corresponding increase in splenic leucopenia and immune suppression. Experimental activation of spinal sympathetic reflexes in SCI mice (e.g., via colorectal distension) elicits $\mathrm{AD}$ and exacerbates immune suppression via a mechanism that involves aberrant accumulation of norepinephrine and glucocorticoids. Reversal of postinjury immune suppression in SCI mice can be achieved by pharmacological inhibition of receptors for norepinephrine and glucocorticoids during the onset and progression of AD. In a human subject with C5 SCI, stimulating the micturition reflex caused $\mathrm{AD}$ with exaggerated catecholamine release and impaired immune function, thus confirming the relevance of the mouse data. These data implicate $\mathrm{AD}$ as a cause of secondary immune deficiency after SCI and reveal novel therapeutic targets for overcoming infectious complications that arise due to deficits in immune function.

\section{Introduction}

Infections impair neurological recovery and increase morbidity and mortality after spinal cord injury (SCI), stroke, and traumatic brain injury (Meisel et al., 2005; Failli et al., 2012). Infectious complications are prevalent in these patient populations and are likely caused by a poorly defined complication referred to as CNS injury-induced immune deficiency syndrome (CIDS; Meisel et al., 2005). The mechanistic basis for CIDS was studied here in the context of SCI.

The hypothalamic-pituitary-adrenal axis and sympathetic nervous system are key regulators of immune function (Irwin and Cole, 2011). In response to psychological or physical stress, hypothalamic neurons release corticotropin-releasing hormone

\footnotetext{
Received May 10, 2013; revised June 19, 2013; accepted June 25, 2013.

Author contributions:Y.Z., J.F.S., C.C.W., A.G.R., M.S.N., and P.G.P. designed research;Y.Z., Z.G., B.R., T.S., S.M.-C., Z.W., A.B., J.W., N.D.P., and M.S.N. performed research; Y.Z., K.H., and M.S.N. analyzed data; Y.Z. and P.G.P. wrote the paper.

This work was supported by the National Institutes of Health (Grant \#R21 NS067260) and the Ray W. Poppleton Endowment (to P.G.P.)

The authors declare no competing financial interests.

Correspondence should be addressed to Phillip G. Popovich, PhD, Center for Brain and Spinal Cord Repair, Department of Neuroscience, Wexner Medical Center at The Ohio State University, 670 Biomedical Research Tower, 460 West 12th Avenue, Columbus, OH 43210. E-mail: phillip.popovich@osumc.edu.

DOI:10.1523/JNEUROSCI.1974-13.2013

Copyright $\odot 2013$ the authors $\quad 0270-6474 / 13 / 3312970-12 \$ 15.00 / 0$
}

into the anterior pituitary, which in turn releases adrenocorticotropic hormone into the bloodstream. Adrenocorticotropic hormone subsequently stimulates release of glucocorticoids (GCs) from the adrenal cortex.

Activation of spinal sympathetic preganglionic neurons (SPNs) causes release of norepinephrine (NE) and GCs from postganglionic nerve terminals and the adrenal gland (Engeland and Arnhold, 2005). SPNs are the source of all sympathetic outflow from the spinal cord (Elenkov et al., 2000). Visceral and somatic afferents activate SPNs, which send cholinergic projections to postganglionic neurons that innervate target organs including blood vessels, lymphoid tissues (e.g., spleen), and the adrenal medulla. SPNs also innervate the adrenal cortex directly, providing a rapid and direct mechanism for enhancing GC release (Engeland and Arnhold, 2005). Physiological concentrations of GCs and NE ensure normal immune function but recurrent or prolonged activation of glucocorticoid receptors (GRs) or $\beta$-2 adrenergic receptors ( $\beta_{2} \mathrm{ARs}$ ) is immunosuppressive (Nance and Sanders, 2007). Therefore, sustained or uncontrolled activation of the sympathetic nervous system will prolong release of GCs and NE and could promote immune suppression.

Injury to the upper thoracic (above T6) or cervical spinal cord removes SPNs from supraspinal control, eliciting in particular constriction of the splanchnic vasculature. When this happens, common somatic or visceral stimuli (e.g., bladder or bowel dis- 
tension) can elicit autonomic dysreflexia (AD), a life-threatening complication of high-level SCI characterized by excessive activation of SPNs with severe episodic hypertension (Inskip et al., 2009). Because the spinal autonomic circuitry that triggers AD also controls immune function, we investigated here whether the onset or progression of AD was associated with chronic secondary immune deficiency (i.e., CIDS).

We report that $\mathrm{AD}$ develops spontaneously in mice with highlevel SCI and is associated with aberrant accumulation of circulating GCs and intrasplenic NE. As the frequency of spontaneous $\mathrm{AD}$ increases, the magnitude of splenic atrophy, splenocyte apoptosis, and immune suppression also increase. The experimental induction of $\mathrm{AD}$ in mice (e.g., colorectal distension) potently suppresses immune function. Moreover, selective $\beta_{2} \mathrm{AR}$ and GR antagonists restore immune function in chronic SCI mice. The clinical relevance of these experimental data was confirmed in a single human subject with C5 SCI. Eliciting a micturition reflex in this subject caused $\mathrm{AD}$ with reflexive release of excess catecholamines and immune suppression. These data indicate that a similar approach could be used to alleviate CIDS and reduce infectious morbidity and mortality after SCI in human subjects.

\section{Materials and Methods}

Animals and SCI. Adult pathogen-free C57BL/6 female mice (10-11 weeks old; The Jackson Laboratory) were maintained in a pathogen-free environment. After acclimating mice to the laboratory environment $(\sim 7$ d), mice were randomized into different experimental groups. Before surgery, mice were anesthetized intraperitoneally with a mixture of ketamine $(80 \mathrm{mg} / \mathrm{kg})$ and xylazine $(40 \mathrm{mg} / \mathrm{kg})$ and then complete spinal cord transection injuries were performed as described previously (Lucin et al., 2007). Briefly, using aseptic technique, a partial laminectomy was performed at vertebral level T3 or T9, after which the periosteum and dura mater were carefully opened. Using iridectomy scissors together with gentle aspiration, the spinal cord was cut, creating a clear separation between the rostral and caudal stumps of transected spinal cord. Complete transections were confirmed visually by gently lifting the rostral and caudal stumps within the spinal canal using a blunt probe. After injury, muscle and skin were sutured separately and then mice were injected with sterile saline ( $2 \mathrm{ml}$, s.c.) and placed individually into warmed HEPAfiltered cages. Sham-injured animals received a laminectomy at T3 but no SCI. Postoperative care included manual bladder expression $2 \times / \mathrm{d}$ and daily antibiotics for the first 7 day post injury (dpi) (gentocin, 5 $\mathrm{mg} / \mathrm{kg}$, s.c.). Dehydration was monitored daily and body weight and urinary $\mathrm{pH}$ were monitored weekly. All procedures were approved by and performed in accordance with the Institutional Laboratory Animal Care and Use Committee at The Ohio State University.

Surgical implantation of telemetry transmitters. The PhysioTel telemetry system with PA-C10 telemetry transmitters (Data Sciences International) was used to quantify cardiovascular changes in sham-injured and SCI mice. PA-C10 transmitters are implantable, eliminating the need for catheter maintenance. Transmitters were prepared as per manufacturer instructions and then implanted in anesthetized mice $3 \mathrm{~d}$ before SCI via a cannulation of the left common carotid artery (CCA). The extravascular portion of the transmitter was placed into a subcutaneous pocket created on the lateral flank. The CCA was exposed through a midline incision on the neck, and the catheter of transmitter was introduced into the CCA through a small incision near the carotid bifurcation and advanced until the sensing region of the catheter was positioned in the aortic arch $(\sim 8-9 \mathrm{~mm}$ from the carotid bifurcation). All surgical procedures were performed using aseptic technique and body temperature was maintained at $\sim 37.5^{\circ} \mathrm{C}$ with a feedback-controlled heating pad (Harvard Apparatus). Between 5 and 35 dpi, blood pressure (BP) and heart rate (HR) were sampled continuously with each data point representing the mean data over $5 \mathrm{~s}$ intervals.

Analysis of spontaneous $A D$. Mice were housed individually in pathogenfree cages placed on top of telemetry receivers. Dataquest data acquisition software (Data Sciences International) was used to acquire HR and BP data between 5 and 35 dpi at $5 \mathrm{~s}$ intervals with implanted telemetry transmitters (see above). MATLAB software (MathWorks) was used to create an algorithm that would detect episodes of spontaneous $\mathrm{AD}$ as described in detail in Figure $1 A$.

Colorectal distension and pinch to intentionally elicit $A D$. To determine how immune function is affected by recurrent episodic activation of $\mathrm{AD}$, a combination of colorectal distension and cutaneous pinch was used to elicit spinal autonomic reflexes. The tips of Hartman hemostats were shielded with polyethylene tubing and then used to pinch the flank below the level of SCI just rostral to the hip joint. To ensure consistent pinch intensity and duration, the hemostat was closed to the first click in every trial for $30 \mathrm{~s}$. Colorectal distension was accomplished using a 4-French, $60 \mathrm{~mm}$ balloon-tipped catheter (Swan-Ganz monitoring catheter model 116F4; Edwards Life Sciences). The catheter was inserted into the anus, positioning the balloon $\sim 1.5 \mathrm{~cm}$ from the anal opening and then securing the catheter to the tail with surgical tape. After securing the catheter, animals were left alone to acclimate for at least $20 \mathrm{~min}$. To elicit $\mathrm{AD}$, the balloon was inflated with $0.3 \mathrm{ml}$ of air for $1 \mathrm{~min}$. Distention was maintained for $1 \mathrm{~min}$ and repeat stimulation occurred after a $30 \mathrm{~min}$ rest. Peak changes in $\mathrm{BP}$ and corresponding $\mathrm{HR}$ were obtained and then compared with baseline values.

Autonomic and immunologic assays in human SCI. Human subject data were obtained with consent as part of a protocol approved by The Medical Sciences Subcommittee for Protection of Human Subjects at the University of Miami School of Medicine. To determine whether a typical micturition episode alters immune function, a healthy subject with chronic ( $>1$ year) C5 neurologically complete tetraplegia (AIS A) fasted overnight, voided his urinary bladder at 5:30 A.M., and was thereafter allowed fluids ad libitum. He underwent venous catheterization at 8:15 A.M. (Jelco Teflon Microtouch catheter $22 \mathrm{G} \times 1$ inch; catheter was kept patent with $0.9 \%$ sterile saline before and after blood collection) and, upon sensing a full bladder, waited 15 min and then stimulated micturition by abdominal tapping. HR was measured using 3-lead ECG and mean arterial pressure $\left(\mathrm{MAP}=\mathrm{BP}_{\text {diastolic }}+1 / 3\right.$ $\left(\mathrm{BP}_{\text {systolic }}-\mathrm{BP}_{\text {diastolic }}\right)$ was assessed by auscultation using a calibrated mercury manometer. No evidence of $\mathrm{AD}$ was evident immediately before micturition. Blood samples drawn 15 min before voiding $(-15)$, immediately upon voiding (0), and at 15 and $30 \mathrm{~min}$ postvoiding were analyzed by flow cytometry for cells bearing markers for helper-inducer $\left(\mathrm{CD} 3{ }^{+} \mathrm{CD} 4{ }^{+}\right)$and suppressor-cytotoxic $\left(\mathrm{CD}^{+}{ }^{+} \mathrm{CD} 8{ }^{+}\right)$subsets. Changes in $\mathrm{CD} 4: \mathrm{CD} 8$ ratios can reflect either immune activation or suppression. In vitro proliferative responses to phytohemagglutinin and pokeweed mitogen, expressed as the stimulation index against unstimulated controls, were used as a measure of lymphocyte function. Plasma NE and epinephrine were assessed by HPLC $15 \mathrm{~min}$ before voiding, at voiding, and at 2, 5, 15, and $30 \mathrm{~min}$ postvoiding. Collection tubes were uniquely coded to mask sampling order and time. Tests were run in duplicate and results are expressed as the average of two measurements.

Ovalbumin immunizations and ELISA analysis. At 18 dpi, mice were injected intraperitoneally with $100 \mu \mathrm{g}$ of ovalbumin (OVA; Sigma) emulsified in an equal volume of TiterMax Gold adjuvant (Sigma). Serum antiOVA IgG1 concentrations were determined $10 \mathrm{~d}$ later (28 dpi) using ELISA. ELISA 96-well plates were coated with $100 \mu \mathrm{g} / \mathrm{ml} \mathrm{OVA} \mathrm{diluted} \mathrm{in} \mathrm{PBS} / 0.02 \%$ sodium azide. After incubating overnight at $4^{\circ} \mathrm{C}$, plates were washed and then blocked $\left(37^{\circ} \mathrm{C}, 2 \mathrm{~h}\right.$ ) with PBS $/ 1 \% \mathrm{BSA}$ (Sigma). After another round of washing (PBS/0.05\% Tween 20), serum samples or standards were pipetted into each well $(20 \mu \mathrm{l} /$ well $)$ with overnight incubation at $4^{\circ} \mathrm{C}$. Standard curves were prepared on each plate. Finally, plates were washed and then alkaline phosphatase-conjugated goat anti-mouse IgG (Southern Biotechnology Associates) diluted $1: 1000$ in $\mathrm{PBS} / 1 \% \mathrm{BSA}\left(37^{\circ} \mathrm{C}, 2 \mathrm{~h}\right)$ was applied. Bound antibodies were visualized by incubating with $1 \mathrm{mg} / \mathrm{ml}$-nitrophenyl phosphate (Sigma). Spectrophotometric readings were performed at $405 \mathrm{~nm}$ (Spectramax kinetic microplate reader; Molecular Devices).

Drugs. Butoxamine (5 mg/kg, i.p., in PBS) and RU486 (5 mg/kg, i.p., in ethanol/sesame oil 1:10) were administrated immediately before SCI and at 1-7 and 14-28 dpi. All mice were immunized with OVA (i.p. $100 \mu \mathrm{g}$ at $18 \mathrm{dpi} 1 \mathrm{~h}$ after drug administration) and then killed at $28 \mathrm{dpi}$.

In vivo MRI. Animals were anesthetized with $2.5 \%$ isoflurane mixed with $1 \mathrm{~L} /$ min carbogen $\left(95 \% \mathrm{O}_{2}\right.$ with $\left.5 \% \mathrm{CO}_{2}\right)$ and then maintained with $1 \%$ isoflurane. Physiologic parameters including respiration and temperature 

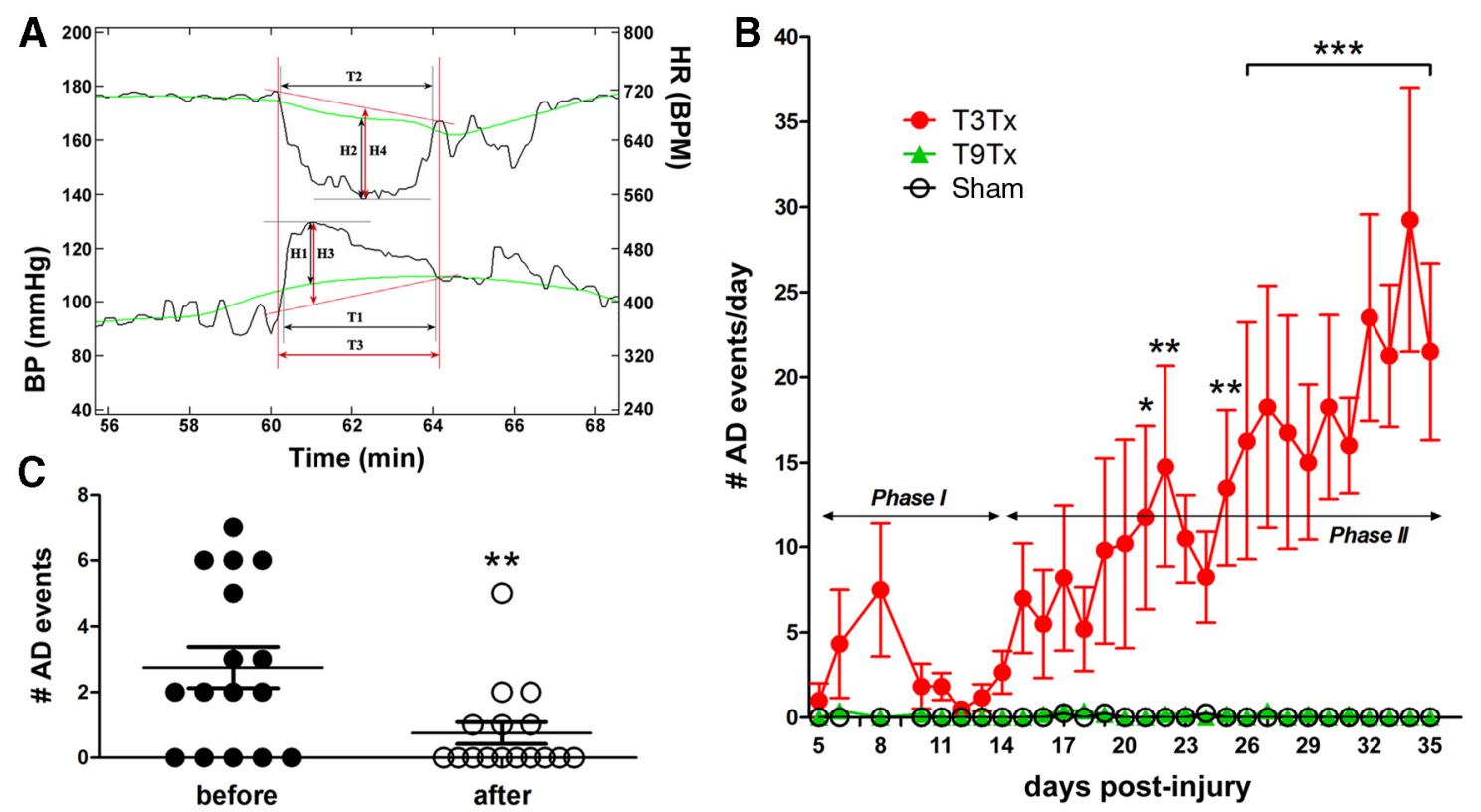

Figure 1. Spontaneous episodes of AD can be detected in SCI mice using in vivo telemetry. $A$, Detection and analysis of spontaneous AD in SCI mice. Using MATLAB, a mathematical algorithm was designed to automatically detect spontaneously occurring events of $A D$ in the HR/BP data. The semiautomated procedure for screening raw data to detect spontaneous $A D$ consisted of three steps. First, establish baselines (green lines) for clipped BP and raw HR data using lowess and robust lowess smoothing filters. Filters were applied in consecutive 6 min epochs (smoothing window). A 6 min window was empirically determined to be optimal (compared with 2, 4, 8, or 10 min; data not shown). Second, simultaneously compare BP and HR data to baseline values. For the computer to automatically register an "event," BP change from baseline (H1) must exceed $10 \mathrm{mmHg}$ and persist above baseline for $>30 \mathrm{~s}$ ( $T 1$ ). During $T 1$, HR must decrease at least $10 \mathrm{bpm}$ below baseline (H2). To register a simultaneous change in HR and BP as a "dysreflexic event," the duration of the BP increase (T1) and HR decrease (T2) must overlap for at least $66 \%$ of the measured interval. Third, export $\mathrm{BP} / \mathrm{HR}$ traces in which suspected $\mathrm{AD}$ events occur, and then visually confirm the event (see $H 3, T 3$, and $H 4$ ). Real spontaneous $\mathrm{AD}$ events with $\mathrm{H3}>20 \mathrm{mmHg}, \mathrm{T3}>30 \mathrm{~s}$, and $H 4>10 \mathrm{BPM}$ are documented in $\boldsymbol{B}$. This final manual confirmation eliminates detection of false-positive events reported by the algorithm. $\boldsymbol{B}$, The number of daily bouts of spontaneous $A D$ increases in $T 3 S C I$ mice in two phases: a transient increase during the first week postinjury (Phase l), followed by a gradual but consistent increase in the total number of daily events after $14 \mathrm{dpi}$ (Phase II). $n=4-7 /$ group; ${ }^{*} p<0.05 ;{ }^{* *} p<0.01 ;{ }^{* * *} p<0.001$ compared with T3 Sham or T9 SCl. C, High-frequency spontaneous AD in T3 SCI mice is associated with a full urinary bladder. Immediately before morning bladder expression, the number of spontaneous dysreflexic events is higher than after bladder expression. Data show individual data points (and group means) for sequentially collected spontaneous $\mathrm{AD}$ events from 0 to $2 \mathrm{~h}$ before and 1 to $3 \mathrm{~h}$ after morning bladder expression in a subset of mice at 26,27 , and 28 dpi. $n=5-6 /$ group; ${ }^{* *} p<0.01$.

were monitored using a small animal monitoring system (model 1025; Small Animals Instruments). A pneumatic pillow was used to monitor respiration. Core temperature was maintained using a warm water bath. Imaging was performed using a Bruker Biospin 94/30 magnet and a 3.5-cm-diameter volume coil. Data were collected using a FLASH sequence $(\mathrm{TR}=180-250$ $\mathrm{ms}$, $\mathrm{TE}=2.3 \mathrm{~ms}$, flip angle $=55^{\circ}$, numerical aperture $\left.=10\right)$ with the following acquisition parameters: FOV $=22 \mathrm{~mm} \times 22 \mathrm{~mm}$, slice thickness $=0.5 \mathrm{~mm}$, matrix size $=256 \times 256$. Slices were obtained as a short axis of spleen. For data analysis, a region-of-interest that included spleen was manually outlined. Spleen volumes were calculated from the outlined region-of-interest.

Serum collection. Whole blood was obtained from awake, unrestrained mice via submandibular bleeds. Samples were collected at 10:00 to 11:00 A.M. the day before surgery (baseline) and then at the designated days postinjury. When bled, mice were handled for $<30 \mathrm{~s}$ and then returned to "recovery" cages. Animals were housed singly in recovery cages and isolated from the area in which mice were being bled. After recovery, mice were group housed as before. Blood was centrifuged and serum transferred into sterile tubes, which were frozen and stored at $-80^{\circ} \mathrm{C}$ until use.

RIA analysis of corticosterone. Serum samples were assayed for total corticosterone (CORT) concentration using a double antibody ${ }^{125}$ I radioimmunoassay kit (MP Biomedicals) according to the manufacturer's instructions and counted on a gamma counter (Packard Instrument). CORT levels were determined in duplicate from a standard curve and expressed in nanograms per milliliter. The minimum detectable limit for this assay was $5 \mathrm{ng} / \mathrm{ml}$.

HPLC quantification of catecholamines. Spleens were quickly removed and then placed in liquid nitrogen to halt degradation of catecholamines. All isolated tissues were stored at $-80^{\circ} \mathrm{C}$ until the time of extraction. Tissue was weighed then quickly homogenized in $1 \mathrm{ml}$ of $0.2 \mathrm{~N}$ acetic acid homogenization buffer ( $1 \mathrm{ml}$ of glacial acetic acid, $26.9 \mu$ l of $0.5 \mathrm{M}$ EDTA,
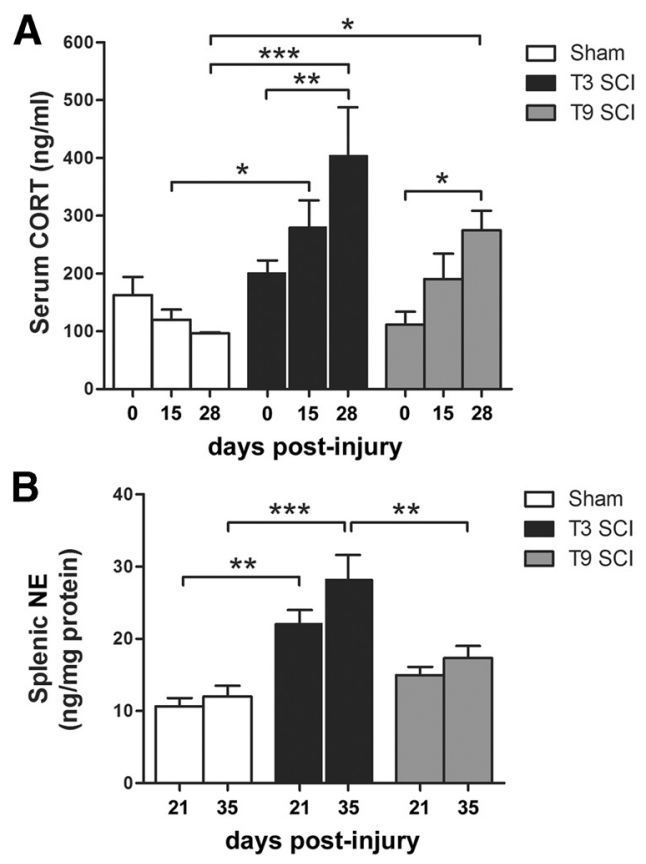

Figure 2. Concentrations of circulating CORT and splenic NE increase as the frequency of spontaneous $A D$ increases. $A$, RIA analysis of CORT levels in serum from mice at 0,15 , and $28 \mathrm{dpi}$ ( $n=3-4$ /group). B, HPLC analysis of splenic NE levels at 21 and $35 \mathrm{dpi}(n=5 /$ group). Extraction efficiency and system recovery was $93.3 \%$. ${ }^{*} p<0.05 ;{ }^{* *} p<0.01 ;{ }^{* * *} p<0.001$. 
A

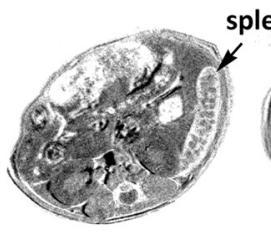

spleen
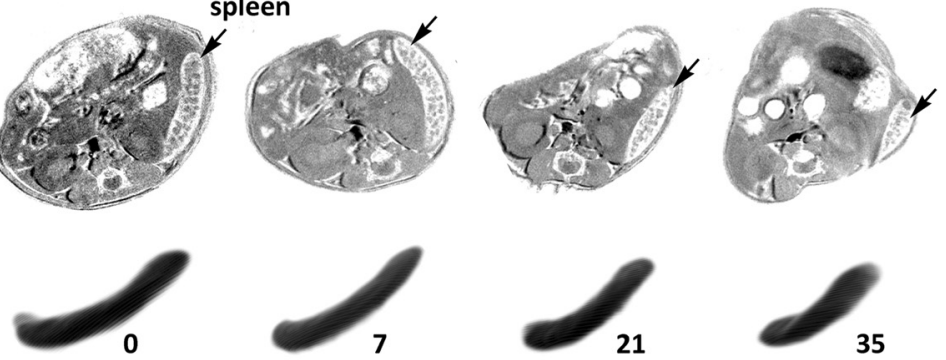

days post-injury

B

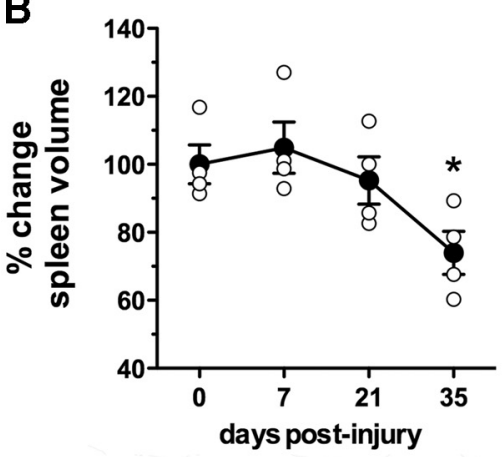

D
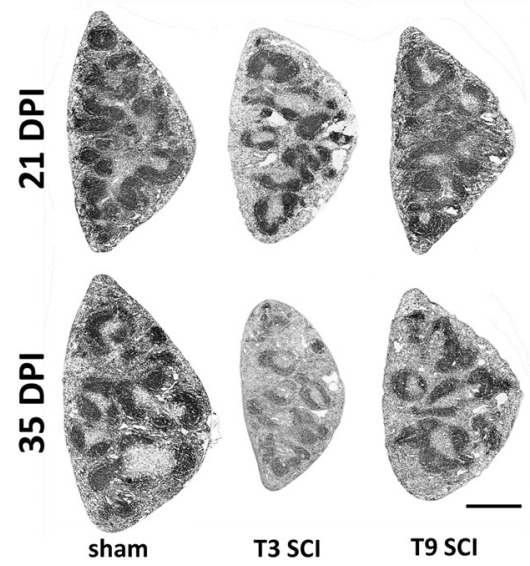

E

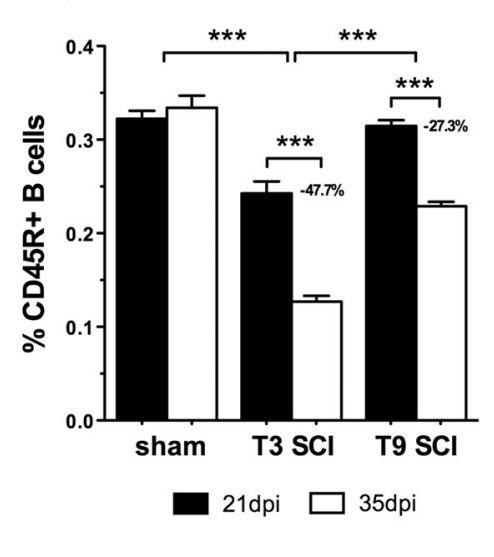

Figure 3. Progressive splenic atrophy and leukopenia occur only after $\mathrm{T} 3 \mathrm{SCl}$ in mice with high-frequency spontaneous $A D$. $A$, Serial in vivo MRI scans (inverted using Photoshop) from a single mouse illustrate the progressive splenic atrophy that occurs after T3 SCl. Top: Two-dimensional view of thoracic cavity highlighting the location and relative size of the spleen at 0, 7, 21, and $35 \mathrm{dpi}$ (arrow). Bottom: Three-dimensional reconstructions of that spleen illustrate the magnitude of splenic atrophy. $\boldsymbol{B}$, Serial measures of spleen volume calculated from MRI images at $0,7,21$, and 35 dpi for each $\mathrm{T} 3 \mathrm{SCl}$ mouse (open circles) then normalized to 0 dpi. $n=4$; ${ }^{*} p<0.05$ compared with 0,7 , or $21 \mathrm{dpi}$; closed symbols represent group mean over time. C, Spleen weight is significantly reduced at 35 dpi only in $\mathrm{T} 3 \mathrm{SCl}$ mice. $n=8-9 ;{ }^{* *} p<0.01 ;{ }^{* * *} p<$ 0.001. D, E, Low-power images and quantification of $\mathrm{CD}_{4} \mathrm{R}^{+} \mathrm{B}$ cells in spleens from $\mathrm{T} 3 \mathrm{SCl}, \mathrm{T} 9 \mathrm{SCl}$, or sham-injured mice reveal progressive B-cell loss between 21 and 35 dpi. Scale bars, $1 \mathrm{~mm} . n=3$ mice/group; quantification made from 3 sections/mouse; ${ }^{* * *} p<0.001$.

0.1 g sodium bisulfite in $99 \mathrm{ml}$ of $\mathrm{ddH}_{2} \mathrm{O}$ ) using glass microhomogenizers. Samples were centrifuged at $700 \times g$ for $5 \mathrm{~min}$. Supernatant catecholamines were extracted by the standard acidified alumina technique with a catecholamine extraction kit (ESA Biosciences) and performed according to the manufacturer's instructions. An extra $100 \mu$ l of supernatant was kept for the BSA protein assay. Quantitative analysis of catecholamines was determined by HPLC using a Waters system mobile phase and electrochemical detector. 3,4-Dihydroxybenzylamine was used as an internal standard for calculation of extraction efficiency.

Immunohistochemistry. Mice were anesthetized and transcardially perfused with cold PBS and then with $4 \%$ paraformaldehyde/PBS. Spleens were dissected, postfixed for $2 \mathrm{~h}$, and then stored in $0.2 \mathrm{M}$ phosphate buffer for $18 \mathrm{~h}$ at $4^{\circ} \mathrm{C}$. The next day, tissues were cryoprotected with $30 \%$ sucrose/

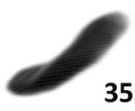

PBS and stored for $48-72 \mathrm{~h}$. Sucrose-infiltrated tissues were embedded in optimal cutting temperature medium (Sakura Finetek) and then rapidly frozen at $-80^{\circ} \mathrm{C}$. Serial coronal cryosections $(10 \mu \mathrm{m})$ of spleen were cut and mounted onto SuperfrostPlus slides (Fisher Scientific). Immunohistochemical stains were performed using antibodies specific for CD45R/B220 (clone RA36B2; AbD Serotec), CD3 (clone 17A2; BD Biosciences), and cleaved Caspase-3 (clone AF835; R\&D Systems). Alexa Fluor 488/546/633 secondary antibodies were used to visualize bound primary antibodies. The relative density of splenic B cells was determined by quantifying the area of CD45R/B220 double-stained cellular profiles within a standardized region of interest in three equidistant sections. Image capture and quantification was performed using an MCID Elite Turnkey system. Final fluorescent images were imported into Adobe Photoshop CS3 and a "levels" adjustment layer was applied to reveal the full tonal range of visible pixels in the RGB histogram.

Flow cytometry. Splenocyte subsets were analyzed using a FACSCanto II flow cytometer with FACSDiva software (BD Biosciences). Briefly, spleens were removed and then bisected. Wet weights of both halves were acquired and then single cell suspensions were made from half the spleen. Viable splenocytes were counted on a hemacytometer and then $1 \times 10^{6}$ cells were incubated with Fc-block (anti-mouse-CD16/CD32; $\mathrm{BD}$ Biosciences) before incubating with directly conjugated antibodies. All samples were stained with the following antibodies: anti-B220-FITC (BD Biosciences), anti-CD23-PE (BD Biosciences), anti-IgM-PerCP-Cy5.5 (BD Biosciences), anti-AA4.1-APC (eBioscience), anti-CD21/35eFluor450 (eBioscience), anti-CD4-FITC (BD Biosciences), anti-CD8-PE (BD Biosciences), anti-CD11b-V450 (BD Biosciences), antiCD11c-APC (BD Biosciences), and ViabilityeFluor780 (eBioscience). At least 10,000 events were collected per sample. Data presented in Figure 4 were derived from the percentage of labeled cells in splenocyte suspensions multiplied by the total splenocyte count. Offline data analyses were completed with FlowJo software (TreeStar).

Statistics. Data are presented as mean \pm SEM for groups and all analyses were performed using GraphPad Prism version 5.0 software. Comparisons between two group means were made using a two-tailed Student's $t$ test. Three or more group means were compared using one-way ANOVA with Tukey's post hoc test. Two-way ANOVA with Bonferroni's post tests were used to compare datasets containing two factors: for example, frequency of spontaneous $\mathrm{AD}$ and time or mean arterial $\mathrm{BP}(\mathrm{MABP}) / \mathrm{HR}$ and time. Group differences were considered statistically significant at $p<0.05$.

\section{Results}

AD develops spontaneously in mice after high-level SCI

A primary goal was to study the interrelationship between naturally occurring (spontaneous) $\mathrm{AD}$ and progressive changes in systemic immune function. Usually, to study $\mathrm{AD}$, scientists measure HR and BP changes elicited by a visceral-sympathetic reflex (e.g., colorectal distension) in SCI rats or mice instrumented with 

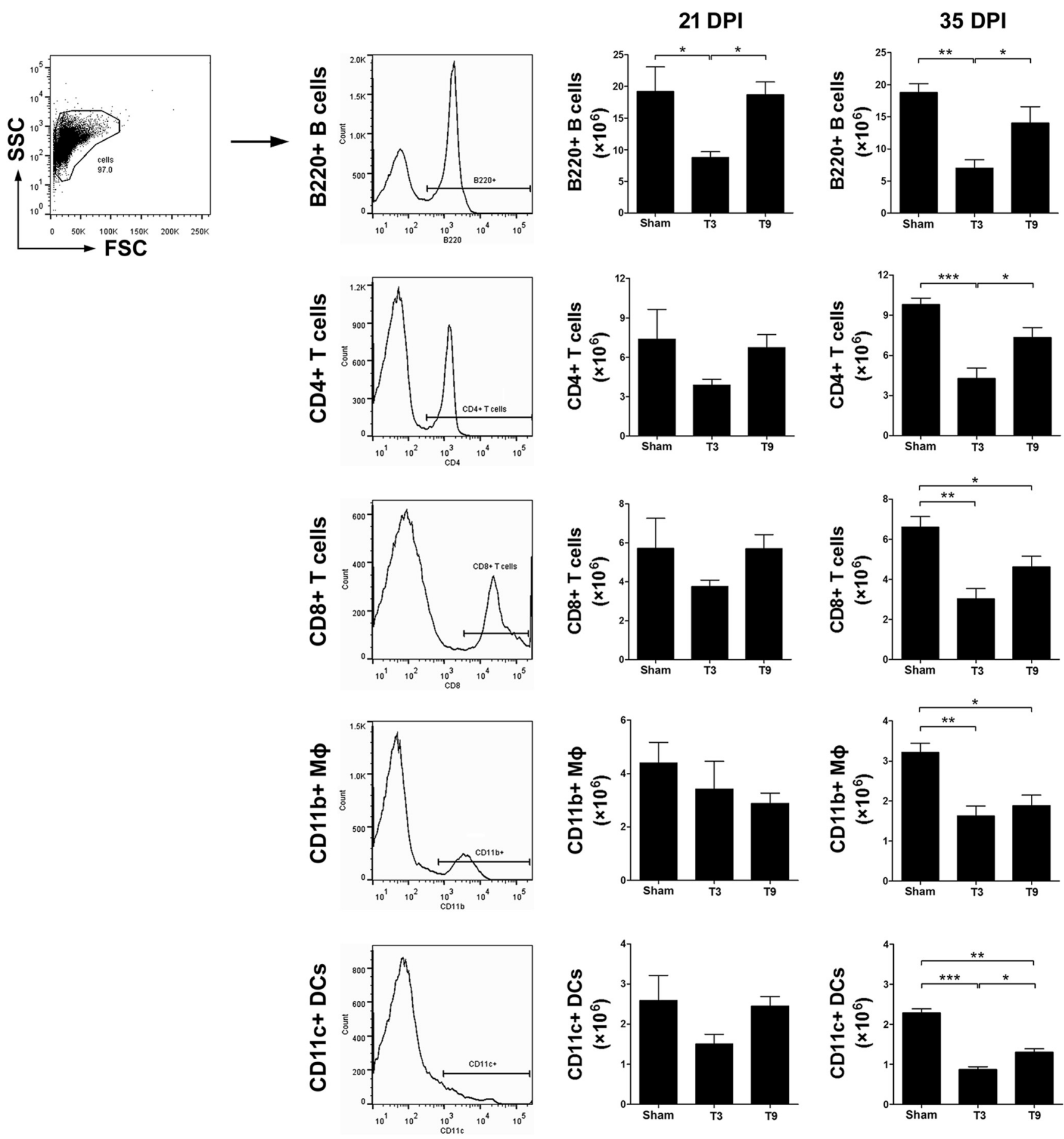

Figure 4. Numbers of all splenic leukocyte subsets are reduced after high-level SCI. Suspensions of splenic leukocytes were phenotyped using specific antibodies. A representative flow cytometry scatter plot of splenic leukocytes (side scatter/SSC vs forward scatter/FSC) and leukocyte-specific histograms is shown to illustrate the approach for quantifying B lymphocytes $\left(B 220^{+}\right), C D 4^{+}$, or $C D 8^{+}$T lymphocytes, macrophages $\left(\mathrm{M} \Phi,\left(\mathrm{CD} 11 \mathrm{~b}^{+}\right)\right.$or dendritic cells $\left(\mathrm{DCS}, \mathrm{CD} 11 \mathrm{c}^{+}\right)$. Bar graphs show mean cell numbers at 21 or 35 dpi after T3 SCl, T9SCl, or T3 Lam. Data are presented as mean cell numbers \pm SEM $\left(\times 10^{6}\right)$. Isotype control antibodies were used to set cursors in histogram plots. Only half a spleen was used for flow cytometry. $n=5 /$ group; ${ }^{*} p<0.05 ;{ }^{* *} p<0.01 ;{ }^{* * *} p<0.001$.

arterial cannulae. Because of the inherent difficulties in maintaining patent cannulae, this type of preparation typically last only a few days. For our purposes, rather than repeatedly remove and insert new cannulae to measure cardiovascular changes, an approach that would undoubtedly cause stress and immune suppression, we adapted an in vivo telemetry technique to detect and quantify daily spontaneous changes in HR and BP in unrestrained sham-injured or SCI mice for up to 5 consecutive weeks (Mayorov et al., 2001; Inskip et al., 2009; Rabchevsky et al., 2012).
A semiautomated custom computer algorithm also was designed to detect bouts of episodic hypertension with concurrent bradycardia (i.e., $\mathrm{AD}$ ) from raw $\mathrm{HR} / \mathrm{BP}$ telemetry traces (Fig. $1 \mathrm{~A}$ ). Using this approach, spontaneous $\mathrm{AD}$ was detected in $\mathrm{T} 3$ but not T9 SCI mice (Fig. 1B). AD develops within 5 to $10 \mathrm{~d}$ dpi and is reminiscent of early onset AD described in tetraplegics (Krassioukov et al., 2003). A second phase of AD develops after 14 dpi with the number of episodes increasing $\sim 10$-fold between 2 and 5 weeks postinjury reaching a maximum of 25-30 epi- 
A
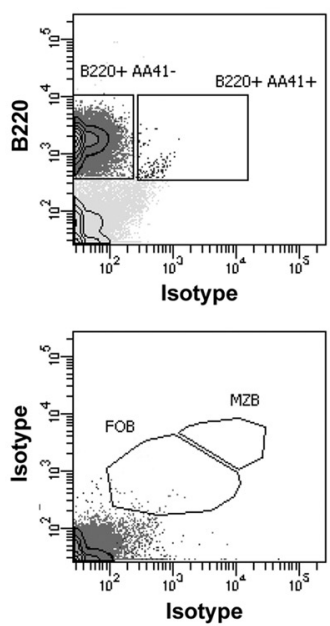

C

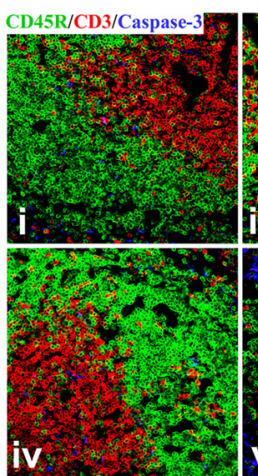

Sham

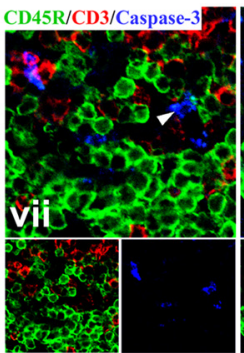

Sham, 21 DPI

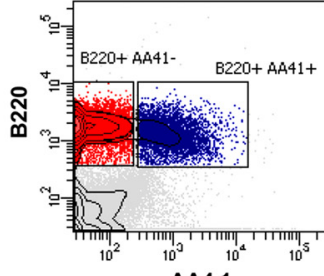

AA4.1

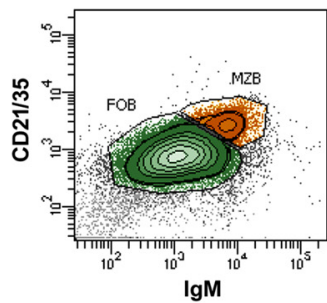

$\lg M$
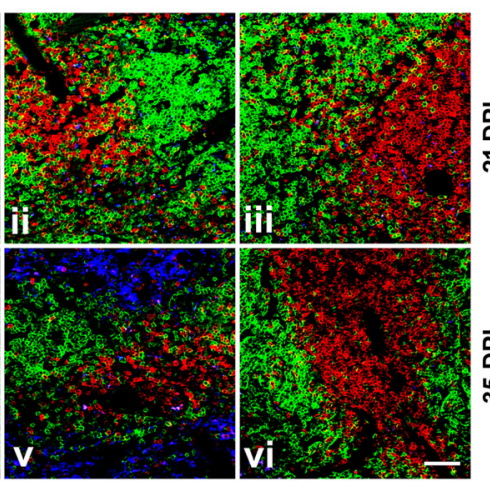

$\mathrm{T9} \mathrm{SCl}$

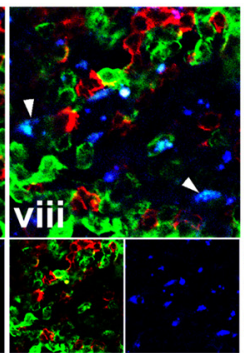

T3 SCI, 21 DPI

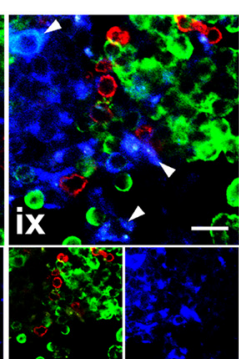

T3 SCI, 35 DPI
B
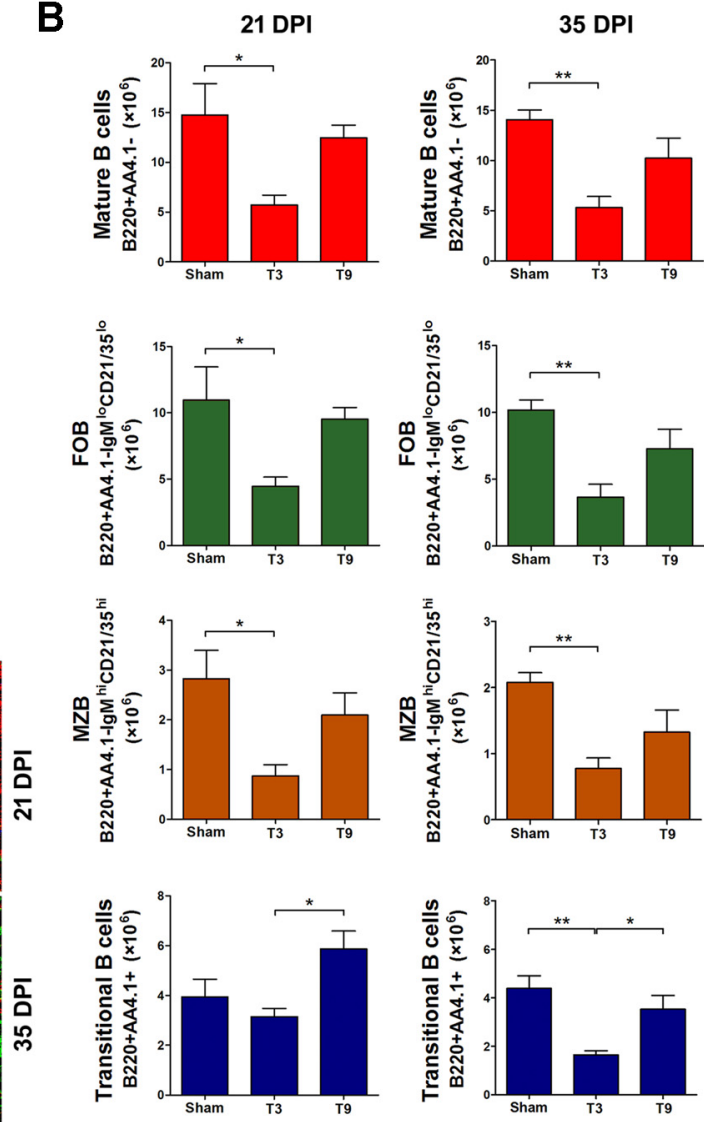

D

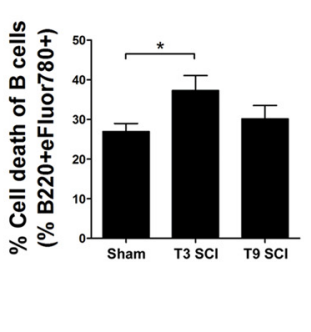

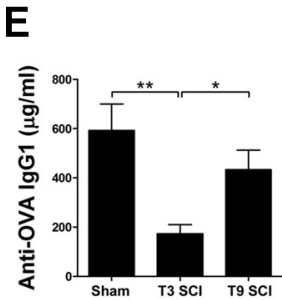

Figure 5. Impaired antigen-specific immunity after high-level SCl is a result of mature B lymphocyte cell death and impaired B-cell genesis. $A$, Representative plots from flow cytometry analysis of B-cell lineages in the spleen. Contour plots show gating strategy to identify mature (red; B220 ${ }^{+} \mathrm{AA4} .1^{-}$) and immature transitional (blue; B220 ${ }^{+} \mathrm{AA4.1}{ }^{+}$) B lymphocytes. Mature B cells can be subdivided into follicular B cells (FOB; green) that express low levels of surface lgM and CD21/35 (IgM ${ }^{\mathrm{lo}} / \mathrm{CD}_{2} 1 / 35^{\mathrm{lo}}$ ) and marginal zone B cells (MZB; brown) that express high levels of surface lgM and CD21/35 (IgM hi/CD21/35 hi). Scatter plots showing isotype control labeling for AA4.1, lgM, and CD21/35 are shown in the left and positively labeled cells are shown in the right scatter plots. Gating strategies to define mature versus immature B cells are shown by box around red-or blue-shaded cell populations. B, Mean number of total B-cell subsets in the spleen at 21 or 35 dpi after T3 SCl, T9 SCl, or T3 Sham. C, Activated caspase- $3^{+}$(blue) cells in splenic white pulp after T3 SCl colocalize with CD45R ${ }^{+}$B lymphocytes (green) and CD3 ${ }^{+}$T lymphocytes (red). Total number of caspase- $3^{+}$cells was consistently highest in T3 SCI (ii, v, viii, ix) spleens compared with spleens from T3 Sham (i, iv, vii) or T9 SCl (iii, vi). More activated caspase-3 ${ }^{+}$cells were detected at 35 dpi $(\boldsymbol{v}, \mathbf{i} \boldsymbol{x})$ than at $21 \mathrm{dpi}(\mathbf{i i}, \boldsymbol{v i i i})$ after T3 SCI. White arrowheads (vii-ix) highlight CD45R ${ }^{+} /$caspase- $3^{+}$B cells. Scale bars: $\boldsymbol{i}$-vi, $50 \mu \mathrm{m}$; vii-ix, $10 \mu \mathrm{m}$. D, Flow cytometry quantification of lymphocyte viability (eFluor780) shows a significant increase in B-cell death only after T3 SCI. E, High-level SCl impairs antibody production. All mice were immunized with OVA (100 $\mu$ g) at $18 \mathrm{dpi}$. Serum anti-0VA IgG1 concentrations were measured by ELISA at $28 \mathrm{dpi} . n=5-6 /$ group; ${ }^{*} p<0.05$; ${ }^{* *} p<0.01$.

sodes/d. In people with high-level SCI, a full bladder often elicits AD (Curt et al., 1997). A similar viscerosympathetic reflex appears to be a natural periodic stimulus for $\mathrm{AD}$ in $\mathrm{SCI}$ mice, because the frequency of spontaneous $\mathrm{AD}$ was significantly reduced $1-3$ $\mathrm{h}$ after morning bladder expression (Fig. 1C).

\section{Progression of $\mathrm{AD}$ predicts chronic immune suppression after SCI}

We showed previously that excess GCs and NE kill leukocytes (Lucin et al., 2007; Lucin et al., 2009). Because recurrent activation of SPNs during bouts of AD should cause GCs and NE to accumulate in the circulation and spleen, we predicted that AD-induced changes in GCs/NE would correlate with the development of post-SCI immune suppression. In support of this hypothesis, we found that blood CORT (endogenous GC in mice) and splenic NE levels increased significantly 15-35 dpi after T3 SCI, when the frequency of spontaneous AD increases $>2$-fold $(\sim 12-25$ episodes/d; Fig. 2$)$. Circulating CORT and splenic NE also were elevated after T9 SCI; however, significant differences were not evident until $28 \mathrm{dpi}$ and then were at least $30 \%$ lower than in T3 SCI mice. 
A
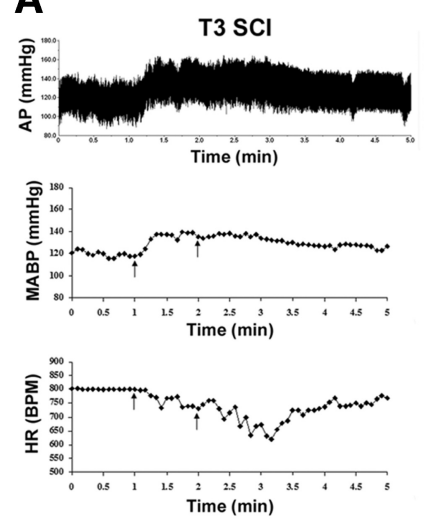

B
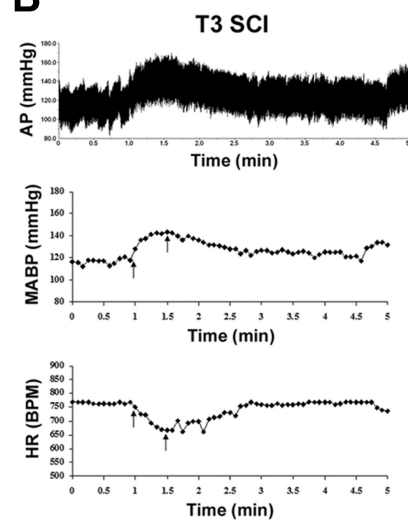

Colorectal distension T9 SCI
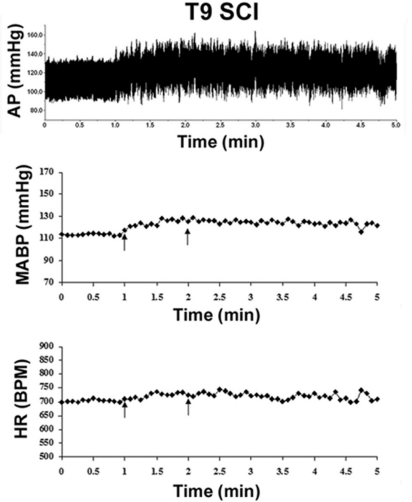

Cutaneous pinch T9 SCI
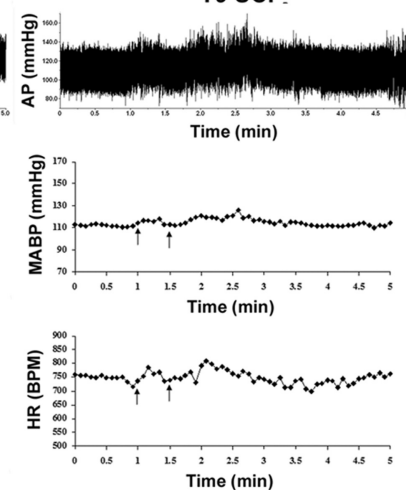
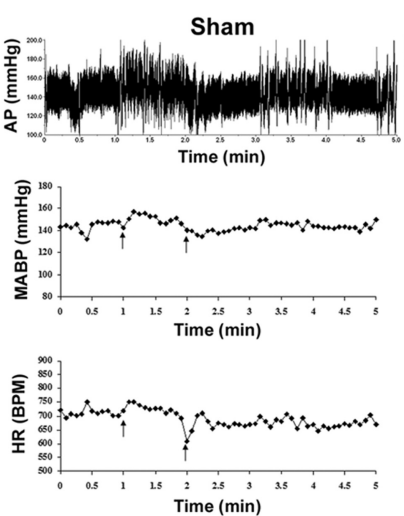

Time $(\min )$
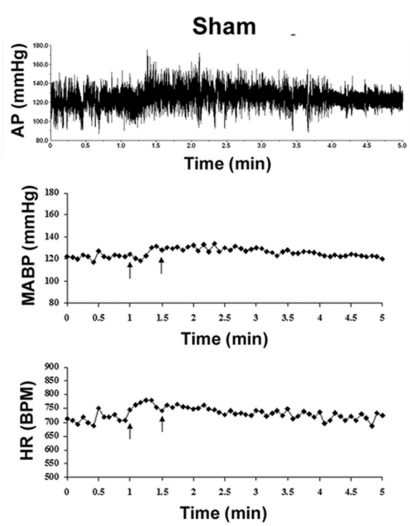

C

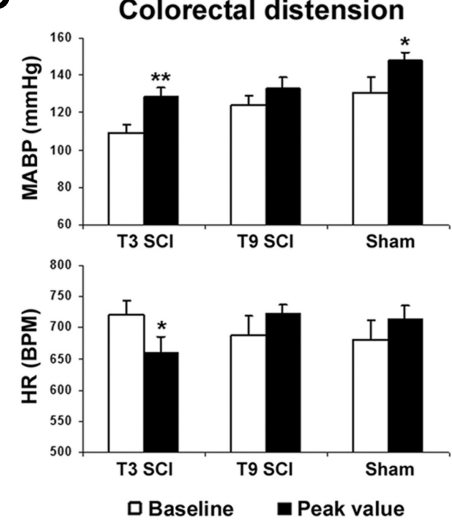

D
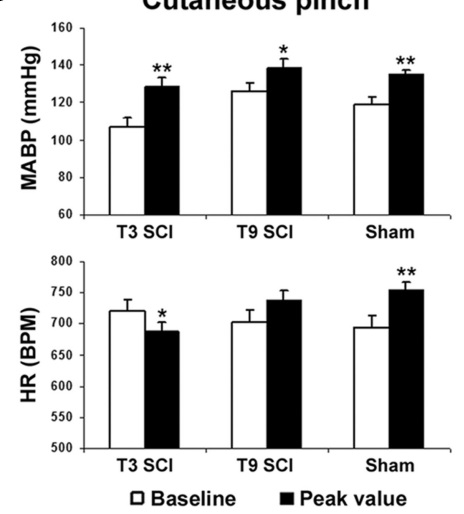

Figure 6. Intentional $A D$ is inducible only in the mice with high-level $S C I$. $A, B$, Representative pulsatile arterial pressure traces after applying colorectal distension or cutaneous pinch in mice at least $14 \mathrm{~d}$ after $\mathrm{SCl}$ or sham surgery (15-20 dpi). Under each trace, MABP and mean HR changes are quantified showing responses to colorectal distension $(\boldsymbol{A})$ or cutaneous pinch (B). Arrows on each trace indicate the start and stop, respectively, for each stimulus. $C, D$, Quantification of MABP and mean $H R$ changes in response to colorectal distension ( $C$ or skin pinch ( $D$ ). Baseline data (white bars) were calculated by averaging measured values over a $10 \mathrm{~s}$ period immediately before stimulation. Black bars represent peak BP values and corresponding $H R$ measured during the time interval spanning stimulus onset until 5 min after cessation of stimulus. $n=6-8 /$ group; $^{*} p<0.05 ;{ }^{* *} p<0.01$ versus baseline.

In T3 SCI mice, postinjury elevations of CORT and NE were associated with progressive splenic atrophy and leucopenia (Fig. 3 ). By 5 weeks postinjury, spleen volume and weight decreased $20-40 \%$ in all T3 SCI mice, a change due in part to marked loss of splenic white pulp (the region containing white blood cells; Fig. 3). Quantitative cytofluorimetric analyses revealed the breadth and magnitude of leukocyte depletion caused by T3 SCI (Fig. 4). Total numbers of splenic leukocytes decreased $50-70 \%$ between 3 and 5 weeks postinjury. All leukocyte subpopulations were affected by T3 SCI; however, B lymphocytes were the most severely depleted at both 21 and 35 dpi (Fig. 4). On average, spleens from T3 SCI mice had $\sim 9-15$ million fewer splenic B cells than shaminjured or T9 SCI mice.

Splenic atrophy and B-cell loss could result from death of mature B cells (Lucin et al., 2007), impaired B-cell genesis (Oropallo et al., 2012), or both. To differentiate between these possibilities, mature B cells and B-cell progenitors were quantified (Fig. 5). Three and 5 weeks after T3 SCI, $\sim 60 \%$ of mature B cells $\left(\mathrm{B} 220^{+} / \mathrm{AA} 4.1^{-}\right)$were lost, in part because of increased apoptosis (Figs. 4, 5A-D).

Two distinct subsets of mature B cells exist in the spleenmarginal zone and follicular B cells (Pillai and Cariappa, 2009). Marginal zone B cells form a first line of defense against circulating antigens, especially environmental pathogens, and readily develop into plasma (antibody-secreting) cells. Follicular B cells are the largest population of circulating $\mathrm{B}$ cells and are needed to generate memory B lymphocytes. After T3 SCI, a significant reduction in total mature B lymphocytes corresponded with significant reductions in both follicular and marginal zone B cells (Fig. $5 B$ ). T9 SCI had only a modest, nonsignificant effect on mature splenic B cells.

Loss of mature B cells is expected to stimulate compensatory lymphopoiesis, culminating in an increase in numbers of immature (transitional) B-cell progenitors $\left(\mathrm{B} 220^{+} \mathrm{AA} 4.1^{+}\right.$) (Woodland and Schmidt, 2005). Three weeks after T9 SCI, the numbers of splenic B-cell progenitors increased $~ 35-50 \%$ compared with sham-injured or T3 SCI mice (Fig. 5B). However, 2 weeks later (35 dpi), B-cell progenitor numbers returned toward baseline. Conversely, after T3 SCI there was a delayed loss of splenic B-cell progenitor cells; at 5 weeks postinjury numbers of splenic B-cell progenitors was reduced $\sim 60 \%$ compared with sham-injured or T9 SCI mice (Fig. 5B).

The ability to produce antibodies against "non-self" proteins requires complex interactions between $B$ and $T$ cells. Because significantly fewer $\mathrm{B}$ and $\mathrm{T}$ cells populate the secondary lymphoid tissues of T3 SCI mice, especially at later times postinjury, when frequent episodes of $\mathrm{AD}$ are evident, we predicted that delayed immunizations would fail to elicit an immune response. Indeed, by $28 \mathrm{dpi}$, T3 SCI mice immunized with a non-self protein failed to generate significant antibody titers (Fig. 5E). T9 SCI mice produced normal concentrations of antibody after immunization (Fig. 5E). 
A

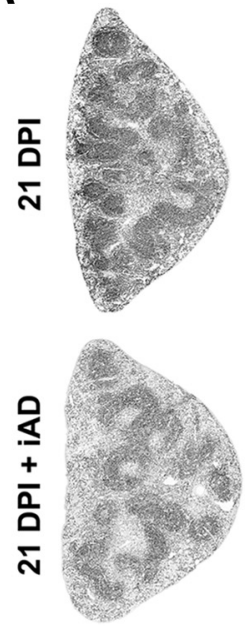

Sham
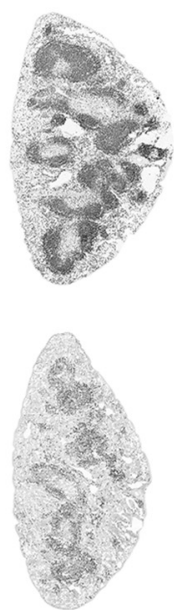

T3 SCI

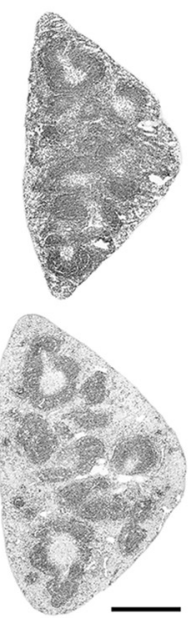

T9 SCl

B

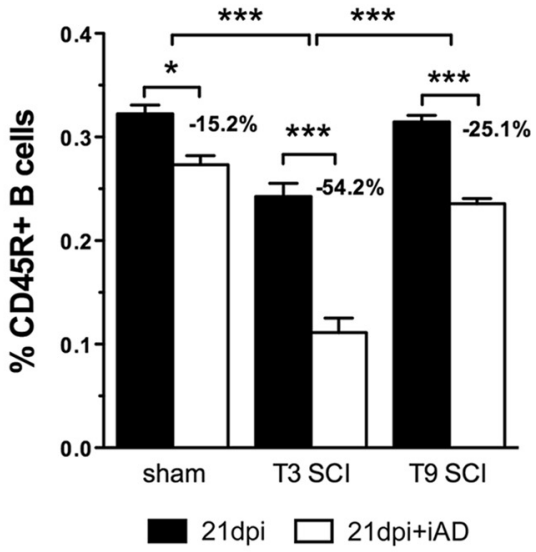

D

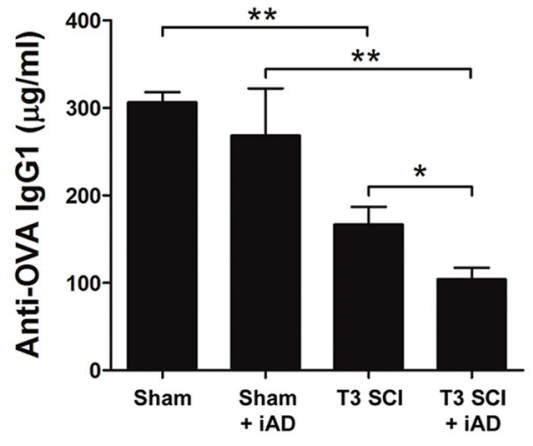

C
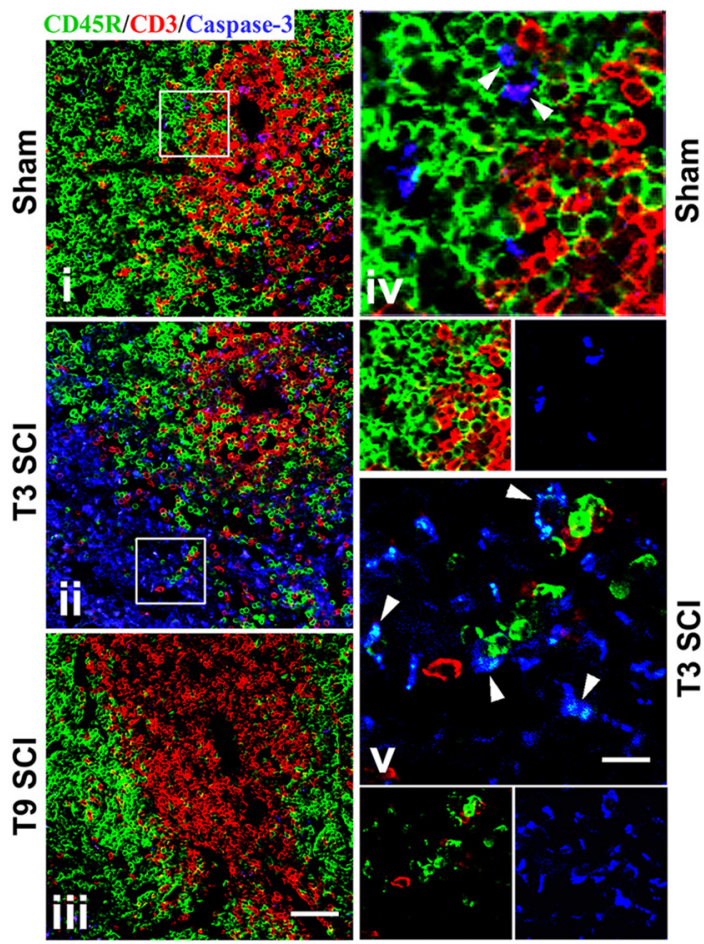

\section{$\frac{\varepsilon}{\text { ๙ }}$}
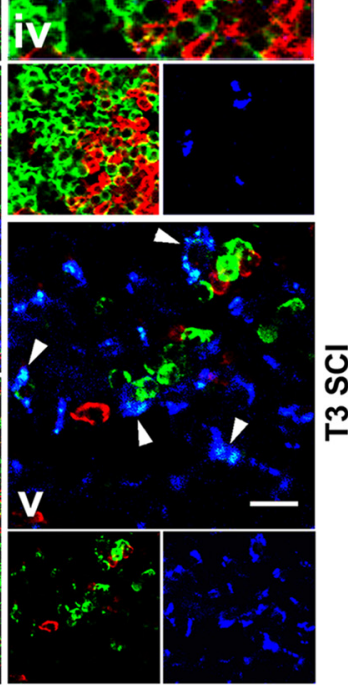

$21 \mathrm{DPI}+\mathrm{iAD}$
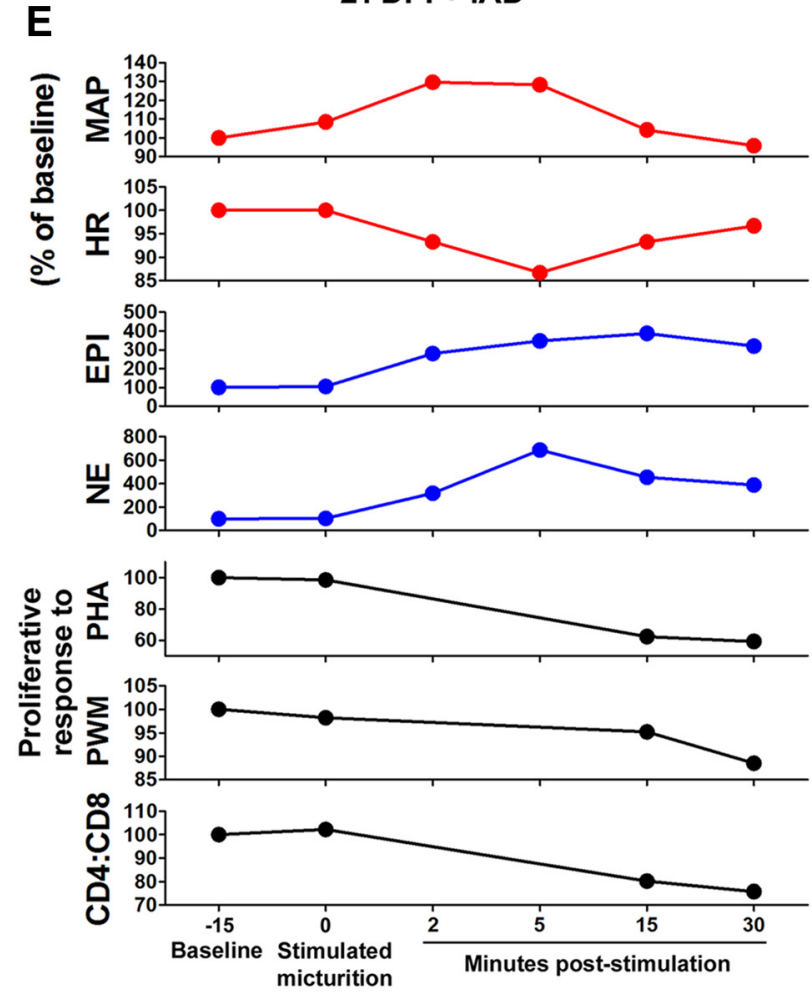

Figure 7. Experimental (i.e., intentional) induction of AD exacerbates post-SCl splenic atrophy and immune suppression in rodents and humans. $\boldsymbol{A}-\boldsymbol{C}$, Colorectal distension and skin pinch cause $\mathrm{AD}$ and exacerbate splenic atrophy and leucopenia in $\mathrm{T} 3 \mathrm{SCI}$ mice. Successive bouts of AD were intentionally triggered using colorectal distension and cutaneous pinch ( $3 \times$ each at 15,16 , and $17 \mathrm{dpi})$ and mice were killed at $21 \mathrm{dpi}$. $A$, Intentional induction of $\mathrm{AD}$ (iAD) caused marked loss of $C D 45 \mathrm{R}^{+}$splenic B lymphocytes. Scale bars, $1 \mathrm{~mm} . \boldsymbol{B}, \mathrm{B}$-cell numbers were reduced $>50 \%$ after $\mathrm{iAD}$ in T3 SCI mice. Only mild nonsignificant effects occurred in sham or T9 SCI mice. $n=3$ mice/group, 3 sections/mouse; ${ }^{*} p<0.05 ;{ }^{* *} p<0.01 ;{ }^{* * *} p<0.001$. C, Immunofluorescent staining of spleen (anti-CD45R, anti-CD3, and activated caspase-3 antibodies) shows that T- and B-cell apoptosis is increased by iAD in T3 SCI mice compared with iAD in sham or T9 SCI mice. White arrowheads delineate double-positive B cells. Scale bars: $\boldsymbol{i}-i i i, 50 \mu \mathrm{m} ; \boldsymbol{i v}, \boldsymbol{v}, 10 \mu \mathrm{m}$. D, OVA-immunized T3SCI mice with iAD produce significantly fewer anti-0VA antibodies than comparable sham control or T3 SCI mice. Serum anti-OVA IgG1 was measured at $28 \mathrm{dpi} . n=4-6 /$ group; ${ }^{*} p<0.05 ;{ }^{* *} p<0.01$. E, Micturition reflex triggered by abdominal tapping in a $C 5$ neurologically complete $\mathrm{SCl}$ volunteer causes mild $\mathrm{AD}$ and is associated with exaggerated reflex catecholamine release and impaired immune function. Mean arterial pressure (MAP; $68-92 \mathrm{~mm} \mathrm{Hg}$ ), HR (52-60 bpm), plasma NE (51-350 pg/ml), and epinephrine (EPI; $7.5-29 \mathrm{pg} / \mathrm{ml})$, in vitro proliferative lymphocyte responses to phytohemaglutinin (PHA) or pokeweed mitogen (PWM), and CD4:CD8 lymphocyte ratios were measured 15 min before voiding, immediately upon voiding (0), and 2,5, 15, and 30 min after voiding. 
A

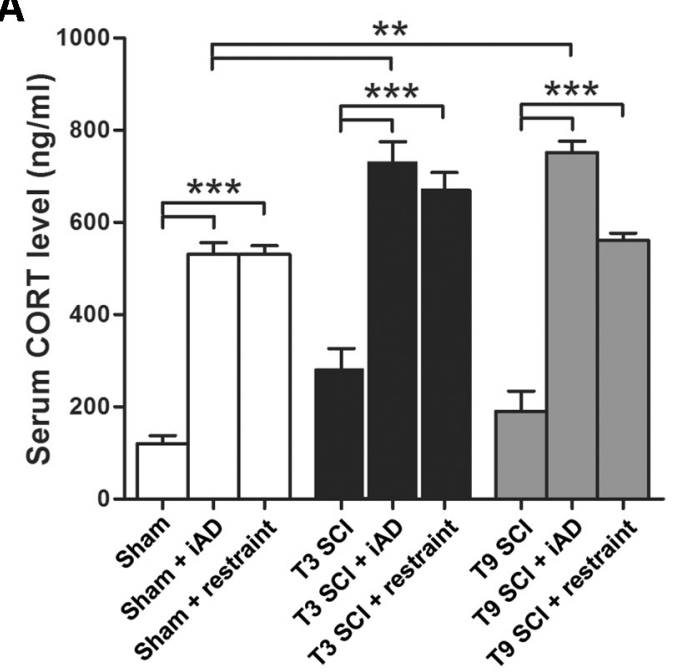

B

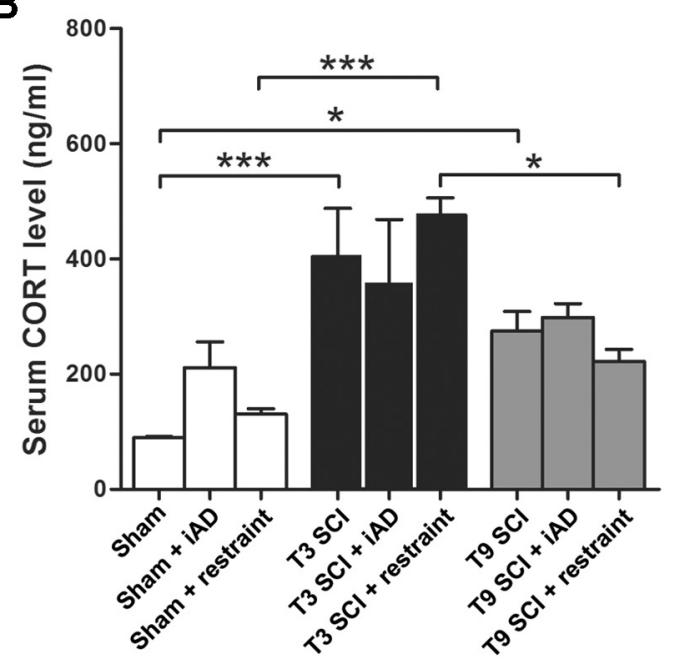

C

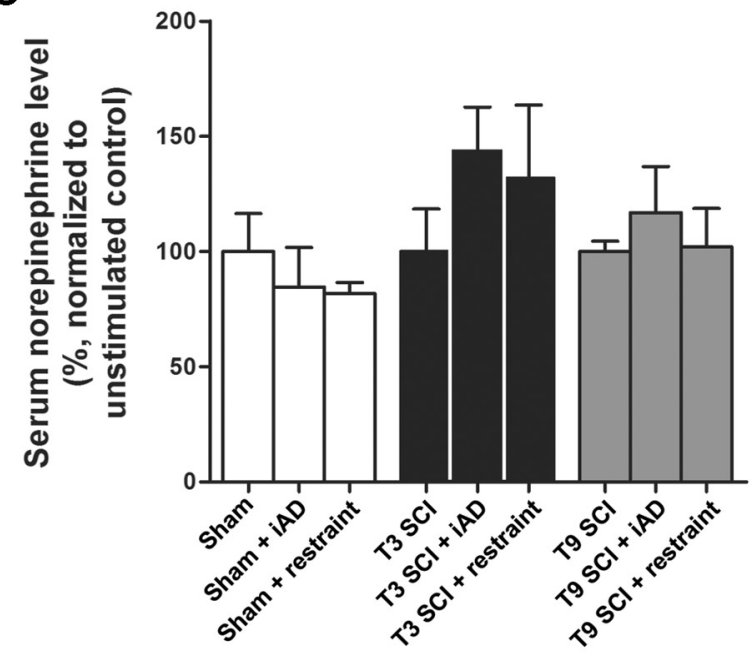

D

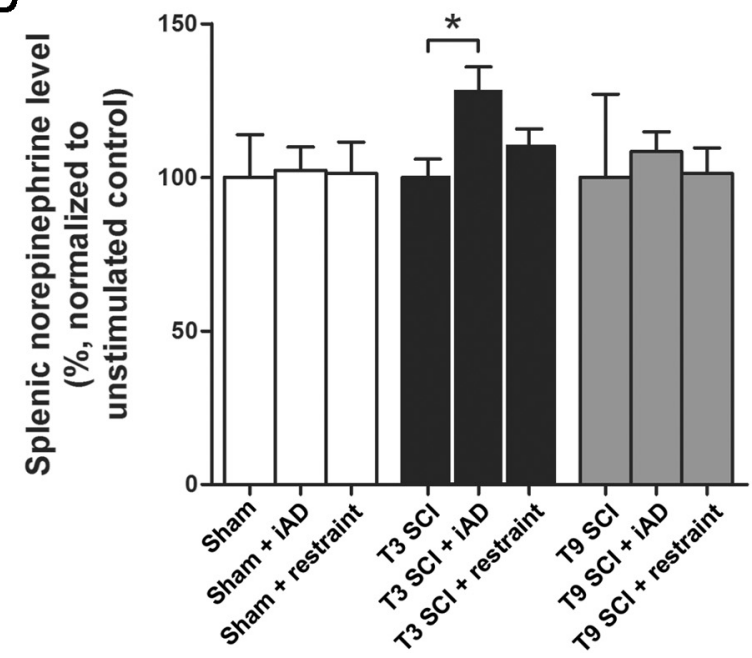

Figure 8. Activation of spinal autonomic reflexes causes sustained elevations of CORT and NE in blood and spleen, respectively, after T3 SCI. Restraint (1 h) served as a stress control. $\boldsymbol{A}, \boldsymbol{B}$, RIA analyses of serum CORT immediately $(\boldsymbol{A})$ or $4 \mathrm{~d}$ after $(\boldsymbol{B})$ after eliciting $A D$ with colorectal distension and pinch (Figs. 6, 7$)$ or restraint. $n=3-4 / \mathrm{group}$. $\boldsymbol{C}, \boldsymbol{D}, \mathrm{HPLC}$ analysis of serum $(\boldsymbol{C})$ and splenic (D) NE $4 \mathrm{~d}$ after colorectal distension/pinch or restraint. $n=4-6 /$ group; percentage extraction efficiency and system recovery $=93.3 \%$; $p<0.05 ;{ }^{* *} p<0.01$; ${ }^{* *} p<0.001$.

\section{AD-dependent immune suppression}

High-level SCI causes AD that is associated temporally with immune suppression. Because there is currently no way to cure $\mathrm{AD}$, it is difficult to prove a cause-effect relationship between $\mathrm{AD}$ and immune suppression. Therefore, we reasoned that if the cumulative effects of episodic $\mathrm{AD}$ are responsible for chronic splenic atrophy and immune suppression, then intentionally eliciting repeat bouts of $\mathrm{AD}$ at earlier times postinjury would recapitulate the effects of chronic spontaneous AD. To test this hypothesis, we used two techniques for eliciting $\mathrm{AD}$, colorectal distension and skin pinch (Inskip et al., 2009). As shown in Figure 6, only in T3 SCI mice did these stimuli elicit hypertension with concurrent bradycardia (i.e., AD).

Because we did not want to introduce a potential immunosuppressive bias that might be associated with activation of visceral or somatic autonomic reflexes (but not the other), successive bouts of $\mathrm{AD}$ were experimentally triggered using both colorectal distension and skin pinch. Between 21 and $35 \mathrm{dpi}$, T3 SCI mice normally experience $\sim 18$ episodes of AD daily, with the frequency increasing as a function of time postinjury (Fig. 1B). To mimic the effects of chronic spontaneously occurring episodic $\mathrm{AD}, \mathrm{SCI}$ or sham-injured mice were exposed to sequential bouts of colorectal distension $(3 \times)$ and then pinch $(3 \times)$ each day for $3 \mathrm{~d}(n=18$ bouts of $\mathrm{AD})$ beginning at $15 \mathrm{dpi}$. As shown in Figure 7 , intentional activation of these $\mathrm{AD}$-inducing spinal autonomic reflexes caused marked splenic white pulp atrophy and B-cell apoptosis after T3 SCI (Fig. 7A-C). Some loss of B cells occurred in the white pulp of all groups, presumably because eliciting spinal autonomic reflexes stimulates the release of immune modulatory GCs and NE. However, in both sham and T9 SCI groups, such hormonal changes were transient (Fig. 8) and a standardized immunization protocol elicited normal B-cell-dependent antibody production (Fig. 7D). In contrast, GCs remained high and splenic NE levels were increased in T3 SCI mice (Fig. 8). Also, the normally immune suppressive effects of T3 SCI were augmented by intentional induction of $\mathrm{AD}$ (Fig. 7D).

An independent clinical study, completed years before in a volunteer subject with chronic ( $>1$ year) C5 SCI (AIS A) confirms the primary observations made in SCI mice. Specifically, eliciting a micturition reflex in this subject caused mild $\mathrm{AD}$ with a profound increase in circulating NE (baseline NE $=51 \mathrm{pg} / \mathrm{ml}$ increased to 162,350 , and $232 \mathrm{pg} / \mathrm{ml}$, at 2, 5, and $15 \mathrm{~min}$ after voiding, respectively) and a decrease in circulating lymphocytes (Fig. 7E). Thirty minutes after voiding, the CD4:CD8 ratio, an 
A

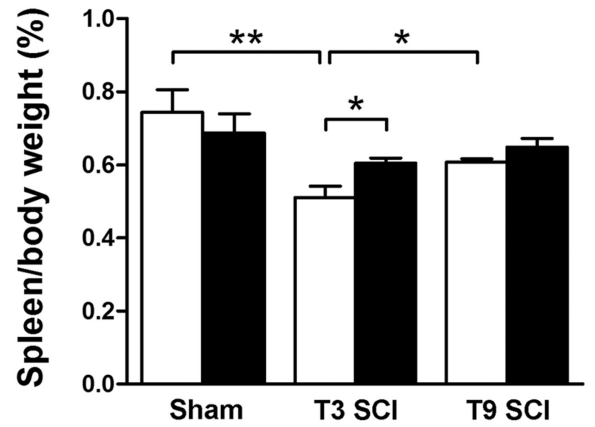

B

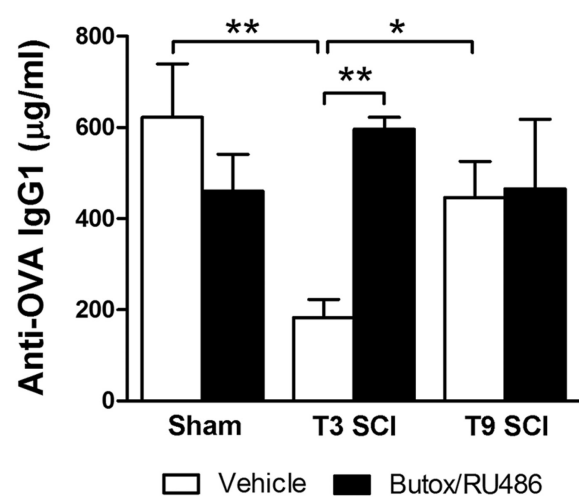

Figure 9. Selective $\beta_{2} A R$ and $G R$ antagonists reverse $A D$-associated chronic immune suppression in T3 SCI mice. Butoxamine (Butox; a selective $\beta 2 A R$ antagonist; $5 \mathrm{mg} / \mathrm{kg}$ ) and RU486 (a glucocorticoid receptor antagonist; $5 \mathrm{mg} / \mathrm{kg}$ ) were injected intraperitoneally daily at $1-7 \mathrm{dpi}$ and $14-28 \mathrm{dpi}$. All mice were immunized at $18 \mathrm{dpi}$ with OVA (100 $\mu \mathrm{g}) 1 \mathrm{~h}$ after injecting drugs. Spleen weight (normalized to body weight) $(\boldsymbol{A})$ and OVA-specific antibodies $(\boldsymbol{B})$ were analyzed in sera at 28 dpi. $n=4-6 /$ group; $^{*} p<0.05$; ${ }^{* *} p<0.01$.

index of immune competence, was reduced $\sim 25 \%$ and the ability to respond to mitogens was impaired relative to baseline (premicturition) function (Fig. $7 E$ ).

Reversing the immune suppressive effects of spontaneous $\mathrm{AD}$ after high-level SCI

The above data prove that eliciting spinal autonomic reflexes in spinalized mice causes $\mathrm{AD}$ and impairs immune function, presumably because immunomodulatory GCs and NE are released into the blood and immune organs with each dysreflexic episode. The cumulative effects of this neurogenic mechanism of immune suppression might be overcome by blocking GC and NE receptors. To test this hypothesis, selective $\beta 2 \mathrm{AR}$ (butoxamine; $5 \mathrm{mg} /$ $\mathrm{kg}$ ) and GR antagonists (RU486; $5 \mathrm{mg} / \mathrm{kg}$ ) were injected intraperitoneally daily at 1-7 dpi and 14-28 dpi. These two intervals correspond with the two phases of AD described in Figure 1B. All mice were immunized with OVA (100 $\mu$ g, i.p.) $1 \mathrm{~h}$ after drug administration at $18 \mathrm{dpi}$, and then anti-OVA antibody titers were quantified at $28 \mathrm{dpi}$. As shown in Figure 7E, anti-OVA IgG1 antibody synthesis was significantly reduced after T3 SCI; however, repeat injections of butoxamine and RU486 significantly reduced splenic atrophy (Fig. 9A) and restored immune function to levels found in sham-injured control mice (Fig. 9B).

\section{Discussion}

Secondary immune deficiency is a serious but poorly understood medical complication after stroke or traumatic injury to the brain or spinal cord (Meisel et al., 2005). A consequence of posttrau- matic immune suppression, referred to as CIDS, is recurrent or chronic infection. Infections impair neurological recovery and often are the cause of death several weeks or months after the primary insult (Meisel et al., 2005; Failli et al., 2012). This is especially true in tetraplegics, in whom immune dysfunction and infectious complications are more prevalent than in paraplegics (Meisel et al., 2005). Tetraplegics with injuries above the level of sympathetic outflow also are prone to developing AD. Novel data presented here implicate $\mathrm{AD}$ as a neurogenic mechanism capable of causing CIDS after SCI.

Using in vivo telemetry, we show here that mice with highlevel SCI spontaneously develop recurring paroxysmal hypertension with bradycardia (i.e., AD). Because AD can occur without bradycardia, the current model likely under represents the true frequency of AD. Nevertheless, the temporal progression of $\mathrm{AD}$ in SCI mice mimics what has been described in humans. Specifically, AD spontaneously develops in two phases: early-onset $\mathrm{AD}$ develops during the first week postinjury, followed by a brief period of quiescence (Krassioukov et al., 2003). Depression of AD lasts only a few days, perhaps due to transient atrophy of spinal sympathetic preganglionic neurons (Krassioukov and Weaver, 1996). A second phase of stable and then enhanced AD develops over the ensuing weeks with the initial reemergence of $\mathrm{AD}$ evident by 2 weeks post-SCI. It is not entirely clear why it takes so long to reestablish $\mathrm{AD}$; however, in rats, these functional changes correspond to evidence of anatomical sprouting and remodeling of spinal circuitry (e.g., sensory afferents and propriospinal axons; Cameron et al., 2006; Hou et al., 2008). Although a similarly detailed anatomical characterization of intraspinal plasticity has not yet been performed in SCI mice, the remarkable physiological similarities among SCI mice, rats, and humans makes the mouse a useful model for studying AD pathophysiology.

After high-level SCI, diverse stimuli, including distension of bladder or colon (Karlsson, 2006), cause reflex activation of SPNs and postganglionic noradrenergic fibers that innervate vasculature, viscera, lymphoid tissues, and the adrenal cortex. Circulating levels of NE also are controlled by SPNs that directly innervate the adrenal medulla. Our current data show that activation of this circuitry in SCI mice causes AD and is associated with an exaggerated reflex catecholamine response and immune suppression.

Previous work from us and others has shown that GCs and NE are released early after stroke, traumatic brain injury, or highlevel SCI and cause splenic atrophy, leukocyte apoptosis, and immune suppression (Oberbeck et al., 2002; Prass et al., 2003; Offner et al., 2006; Lucin et al., 2007). However, because extracellular NE is metabolized within seconds to minutes, gross structural changes in spleen and immune suppression were considered as temporary adaptations to the acute injury (Mitchell et al., 1994). For example, organisms regulate blood volume distribution after severe trauma via splenic contraction (Hurford et al., 1996). Here, using serial in vivo MRI, we show that splenic atrophy is a dynamic but protracted process that is caused by recurrent activation of the same spinal autonomic reflexes that trigger $\mathrm{AD}$. Within the atrophied spleen, accumulation of NE is likely a reflection of enhanced splenic nerve activity; however, a contribution from the adrenal medulla cannot be excluded (Kopin et al., 1978). Regardless of source, excess NE together with an increase in circulating GCs causes widespread apoptosis of inflammatory cells in the splenic white pulp (Lucin et al., 2009).

In humans with SCI, micturition is the most frequent $\mathrm{AD}$ inducing stimulus, recurring $\sim 3-6 \mathrm{~h}$ daily. Usually, the onset of $\mathrm{AD}$ is accompanied by symptoms including headache or sweating above the level of injury; however, $\mathrm{AD}$ also can be "silent" or 
without symptoms. Silent $\mathrm{AD}$ is triggered by routine bowel and bladder care in susceptible patient populations (Linsenmeyer et al., 1996; Giannantoni et al., 1998; Kirshblum et al., 2002). Therefore, the overall frequency of $\mathrm{AD}$ is underappreciated, as is the potential for this aberrant reflex to modulate immune function. In a previous study, data from a human subject show that a single micturition reflex causes $\mathrm{AD}$ with exaggerated catecholamine release and impaired immune function. At a minimum, these human data confirm the potential clinical relevance of our findings from the mouse SCI model.

$\mathrm{B}$ and $\mathrm{T}$ lymphocytes are especially sensitive to the effects of NE and GCs (Lucin et al., 2009). Activation and differentiation of naive $B$ cells occurs within specialized microdomains of secondary lymphoid tissues; there, B cells interact with $\mathrm{T}$ cells and dendritic cells to mount immune responses against virus and bacteria. Of paramount importance in this response is the production of antibodies. Antibodies bind a range of antigens including proteins, carbohydrates, and lipid moieties found on pathogens. Vaccines are designed to elicit B-cell activation and stimulate antibody production. We showed previously that splenic B-cell numbers are significantly reduced early after highlevel SCI (Lucin et al., 2007). Oropallo et al. (2012) confirmed and extended those data showing that mature follicular, but not marginal zone B cells, are preferentially lost after SCI. Here, we show that both mature follicular and marginal zone $\mathrm{B}$ cells are lost and immature transitional B cell subsets $\left(\mathrm{B} 220^{+} / \mathrm{AA} 4.1^{+}\right.$) fail to repopulate the spleen after T3 SCI for up to 5 weeks postinjury. Lymphocyte depletion of this magnitude would normally stimulate lymphopoiesis and migration of immature B cells from bone marrow.

$\mathrm{AD}$ is prevalent after high-level SCI, but it is not ubiquitous and not all who suffer from $\mathrm{AD}$ incur life-threatening infections or respond poorly to vaccines. Nevertheless, when AD develops, close monitoring of cardiovascular function might predict the onset of CIDS. For example, changes in HR variability can be easily measured using portable Holter monitors. In acute stroke patients, HR variability data can predict infectious complications (Günther et al., 2012). Similar analyses are feasible after SCI and can predict autonomic dysfunction (Inskip et al., 2012). Whether immune deficiency syndromes correlate with or can be predicted by HR variability after SCI requires additional research.

Overall, our present data provide a mechanism to explain why people with high-level SCI develop CIDS and clinically significant infectious complications. Specifically, we show that spontaneous uncontrolled activation of AD causes immune suppression, in part by releasing into the blood and immune organs high levels of immunomodulatory hormones that nonselectively kill mature and immature splenic leukocytes. Our data also show that optimal responses to vaccination can be achieved after high-level SCI by blocking activation of lymphocyte $\beta_{2}$ ARs and GRs. Other regimens of adrenoreceptor blockade have proven to be similarly effective in potentiating immune responses after stroke (Prass et al., 2003; Ajmo et al., 2009). Complementary mechanisms of immune suppression should be considered in the future, including studies designed to understand the effects of sustained SNS activation of invariant natural killer $\mathrm{T}$ cells in the liver or reflex activation of cholinergic anti-inflammatory $\mathrm{T}$ cells in the spleen (Rosas-Ballina et al., 2011; Wong et al., 2011). Both pathways are likely to be enhanced after high-level SCI and could represent therapeutic targets for reversing CIDS.

\section{References}

Ajmo CT Jr, Collier LA, Leonardo CC, Hall AA, Green SM, Womble TA, Cuevas J, Willing AE, Pennypacker KR (2009) Blockade of adrenoreceptors inhibits the splenic response to stroke. Exp Neurol 218:47-55. CrossRef Medline

Cameron AA, Smith GM, Randall DC, Brown DR, Rabchevsky AG (2006) Genetic manipulation of intraspinal plasticity after spinal cord injury alters the severity of autonomic dysreflexia. J Neurosci 26:2923-2932. CrossRef Medline

Curt A, Nitsche B, Rodic B, Schurch B, Dietz V (1997) Assessment of autonomic dysreflexia in patients with spinal cord injury. J Neurol Neurosurg Psychiatry 62:473-477. CrossRef Medline

Elenkov IJ, Wilder RL, Chrousos GP, Vizi ES (2000) The sympathetic nerve-an integrative interface between two supersystems: the brain and the immune system. Pharmacol Rev 52:595-638. Medline

Engeland WC, Arnhold MM (2005) Neural circuitry in the regulation of adrenal corticosterone rhythmicity. Endocrine 28:325-332. CrossRef Medline

Failli V, Kopp MA, Gericke C, Martus P, Klingbeil S, Brommer B, Laginha I, Chen Y, DeVivo MJ, Dirnagl U, Schwab JM (2012) Functional neurological recovery after spinal cord injury is impaired in patients with infections. Brain 135:3238-3250. CrossRef Medline

Giannantoni A, Di Stasi SM, Scivoletto G, Mollo A, Silecchia A, Fuoco U, Vespasiani G (1998) Autonomic dysreflexia during urodynamics. Spinal Cord 36:756-760. CrossRef Medline

Günther A, Salzmann I, Nowack S, Schwab M, Surber R, Hoyer H, Witte OW, Hoyer D (2012) Heart rate variability-a potential early marker of subacute post-stroke infections. Acta Neurol Scand 126:189-196. CrossRef Medline

Hou S, Duale H, Cameron AA, Abshire SM, Lyttle TS, Rabchevsky AG (2008) Plasticity of lumbosacral propriospinal neurons is associated with the development of autonomic dysreflexia after thoracic spinal cord transection. J Comp Neurol 509:382-399. CrossRef Medline

Hurford WE, Hochachka PW, Schneider RC, Guyton GP, Stanek KS, Zapol DG, Liggins GC, Zapol WM (1996) Splenic contraction, catecholamine release, and blood volume redistribution during diving in the Weddell seal. J Appl Physiol 80:298-306. Medline

Inskip JA, Ramer LM, Ramer MS, Krassioukov AV (2009) Autonomic assessment of animals with spinal cord injury: tools, techniques and translation. Spinal Cord 47:2-35. CrossRef Medline

Inskip JA, Ramer LM, Ramer MS, Krassioukov AV, Claydon VE (2012) Spectral analyses of cardiovascular control in rodents with spinal cord injury. J Neurotrauma 29:1638-1649. CrossRef Medline

Irwin MR, Cole SW (2011) Reciprocal regulation of the neural and innate immune systems. Nat Rev Immunol 11:625-632. CrossRef Medline

Karlsson AK (2006) Autonomic dysfunction in spinal cord injury: clinical presentation of symptoms and signs. Prog Brain Res 152:1-8. CrossRef Medline

Kirshblum SC, House JG, O’Connor KC (2002) Silent autonomic dysreflexia during a routine bowel program in persons with traumatic spinal cord injury: a preliminary study. Arch Phys Med Rehabil 83:1774-1776. CrossRef Medline

Kopin IJ, Lake RC, Ziegler M (1978) Plasma levels of norepinephrine. Ann Intern Med 88:671-680. CrossRef Medline

Krassioukov AV, Weaver LC (1996) Morphological changes in sympathetic preganglionic neurons after spinal cord injury in rats. Neuroscience 70: 211-225. CrossRef Medline

Krassioukov AV, Furlan JC, Fehlings MG (2003) Autonomic dysreflexia in acute spinal cord injury: an under-recognized clinical entity. J Neurotrauma 20:707-716. CrossRef Medline

Linsenmeyer TA, Campagnolo DI, Chou IH (1996) Silent autonomic dysreflexia during voiding in men with spinal cord injuries. J Urol 155:519-522. CrossRef Medline

Lucin KM, Sanders VM, Jones TB, Malarkey WB, Popovich PG (2007) Impaired antibody synthesis after spinal cord injury is level dependent and is due to sympathetic nervous system dysregulation. Exp Neurol 207:75-84. CrossRef Medline

Lucin KM, Sanders VM, Popovich PG (2009) Stress hormones collaborate to induce lymphocyte apoptosis after high level spinal cord injury. J Neurochem 110:1409-1421. CrossRef Medline

Mayorov DN, Adams MA, Krassioukov AV (2001) Telemetric blood pres- 
sure monitoring in conscious rats before and after compression injury of spinal cord. J Neurotrauma 18:727-736. CrossRef Medline

Meisel C, Schwab JM, Prass K, Meisel A, Dirnagl U (2005) Central nervous system injury-induced immune deficiency syndrome. Nat Rev Neurosci 6:775-786. CrossRef Medline

Mitchell K, Oke AF, Adams RN (1994) In vivo dynamics of norepinephrine release-reuptake in multiple terminal field regions of rat brain. J Neurochem 63:917-926. CrossRef Medline

Nance DM, Sanders VM (2007) Autonomic innervation and regulation of the immune system (1987-2007). Brain Behav Immun 21:736-745. CrossRef Medline

Oberbeck R, van Griensven M, Nickel E, Tschernig T, Wittwer T, Pape HC (2002) Influence of beta-adrenoceptor antagonists on hemorrhageinduced cellular immune suppression. Shock 18:331-335. CrossRef Medline

Offner H, Subramanian S, Parker SM, Wang C, Afentoulis ME, Lewis A, Vandenbark AA, Hurn PD (2006) Splenic atrophy in experimental stroke is accompanied by increased regulatory $\mathrm{T}$ cells and circulating macrophages. J Immunol 176:6523-6531. Medline

Oropallo MA, Held KS, Goenka R, Ahmad SA, O’Neill PJ, Steward O, Lane TE, Cancro MP (2012) Chronic spinal cord injury impairs primary antibody responses but spares existing humoral immunity in mice. J Immunol 188:5257-5266. CrossRef Medline
Pillai S, Cariappa A (2009) The follicular versus marginal zone B lymphocyte cell fate decision. Nat Rev Immunol 9:767-777. CrossRef Medline

Prass K, Meisel C, Höflich C, Braun J, Halle E, Wolf T, Ruscher K, Victorov IV, Priller J, Dirnagl U, Volk HD, Meisel A (2003) Stroke-induced immunodeficiency promotes spontaneous bacterial infections and is mediated by sympathetic activation reversal by poststroke $\mathrm{T}$ helper cell type 1-like immunostimulation. J Exp Med 198:725-736. CrossRef Medline

Rabchevsky AG, Patel SP, Lyttle TS, Eldahan KC, O’Dell CR, Zhang Y, Popovich PG, Kitzman PH, Donohue KD (2012) Effects of gabapentin on muscle spasticity and both induced as well as spontaneous autonomic dysreflexia after complete spinal cord injury. Front Physiol 3:329. CrossRef Medline

Rosas-Ballina M, Olofsson PS, Ochani M, Valdés-Ferrer SI, Levine YA, Reardon C, Tusche MW, Pavlov VA, Andersson U, Chavan S, Mak TW, Tracey KJ (2011) Acetylcholine-synthesizing T cells relay neural signals in a vagus nerve circuit. Science 334:98-101. CrossRef Medline

Wong CH, Jenne CN, Lee WY, Léger C, Kubes P (2011) Functional innervation of hepatic iNKT cells is immunosuppressive following stroke. Science 334:101-105. CrossRef Medline

Woodland RT, Schmidt MR (2005) Homeostatic proliferation of B cells. Semin Immunol 17:209-217. CrossRef Medline 